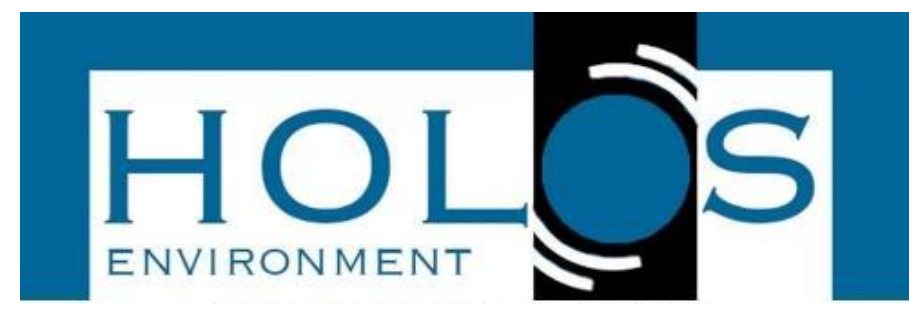

\title{
O ISOLAMENTO SOCIAL EFETIVAMENTE IMPACTA A QUALIDADE DO AR? O CASO DE CAMPINAS - SP
}

\section{DOES SOCIAL ISOLATION ACTUALLY IMPACT AIR QUALITY? THE CASE OF CAMPINAS - SP}

\author{
Rafael Possari Macorin1; Danilo Covaes Nogarotto1; Simone Andréa Pozza ${ }^{1}$
}

Artigo recebido em: 12/11/2021 e aceito para publicação em: 16/11/2021.

DOI: http://doi.org/10.14295/holos.v21i3.12456

\begin{abstract}
Resumo: A poluição do ar é considerada um dos maiores problemas ambientais e de saúde do mundo. Ao longo dos anos ocorreram diversos eventos que foram responsáveis por causar alterações na qualidade do ar. Com o surto da doença COVID-19 e o rápido aumento do número de casos positivos que se espalhou pelo mundo, tornando a doença uma preocupação em escala internacional, diversos países adotaram medidas de restrição para diminuir a propagação do vírus. No Brasil, após declarado estado de emergência à saúde pública no país, foi adotado o distanciamento social, em março de 2020 . Neste estudo foi analisado o impacto das medidas de distanciamento social na qualidade do ar e a variação nas concentrações de material particulado (MP10 e MP2,5), em três estações de monitoramento na cidade de Campinas (SP). Foram comparados dados do período de quarentena, do ano de 2020 e os valores obtidos no mesmo período de 2019, antes da pandemia. Os níveis de material particulado foram reduzidos no começo da quarentena e depois apresentaram um aumento, devido a redução da taxa de isolamento social na cidade. O estudo mostrou, por meio do modelo de regressão linear, que existe relação significativa entre a concentração de material particulado e a taxa de isolamento social, porém foi uma fraca correlação.
\end{abstract}

Palavras-chave: COVID-19. Distanciamento social. Poluição do ar. Material particulado.

\begin{abstract}
Air pollution is considered one of the biggest environmental and health problems in the world. Over the years, several events occurred that were responsible for causing changes in air quality. With the outbreak of the COVID-19 disease and the rapid increase in the number of positive cases that have spread around the world, making the disease a concern on an international scale, several countries have adopted restriction measures to reduce the spread of the virus. Brazil adopted the social distancing in March 2020, after the declaration of public health emergency state. In this study, the impact of social distancing measures on air quality and the variation in particulate matter concentrations was analyzed (PM10 and PM2.5) in three monitoring stations in the city of Campinas (SP). Data from the quarantine period in 2020, and the values from the same period in 2019, before the pandemic, were compared. Particulate matter levels were reduced at the quarantine beginning and increased due to the reduction in the rate of social isolation in the city. The study showed, through the linear regression model, that there is a relationship between the concentration of particulate matter and the rate of social isolation, but it was a weak correlation.
\end{abstract}

Keywords: COVID-19. Social distance. Air pollution. Particulate matter.

${ }^{1}$ Faculdade de Tecnologia (FT)/Universidade Estadual de Campinas (Unicamp), Limeira, SP. E-mails: (rafaelpmacorin@gmail.com, danilocn@unicamp.br, spozza@unicamp.br) 


\section{INTRODUÇÃO}

Atualmente a poluição do ar é considerada um dos maiores problemas ambientais e de saúde do mundo, e é um dos maiores fatores de risco das principais causas de morte, incluindo doenças cardíacas, derrames, infecções respiratórias, câncer de pulmão, entre outras (DOCKERY; EVANS, 2017; RITCHIE; ROSER, 2017). Foi realizado um estudo sobre Carga de Doença Global (CDG) pelo Instituto de Métrica e Avaliação em Saúde (IMAS) indicando que a poluição atmosférica foi responsável por cerca de 5 milhões de mortes em todo o mundo, em 2017, correspondendo a 9\% das mortes naquele ano (RITCHIE; ROSER, 2017).

Um dos principais contribuintes para problemas à saúde, devido à poluição do ar, é o material particulado (MP), que são partículas muito finas de sólidos ou líquidos suspensos no ar. As partículas inaláveis grossas, conhecidas como $\mathrm{MP}_{10}$ (partículas com o diâmetro inferior a $10 \mu \mathrm{m}$ ) podem ser acumuladas nas vias aéreas superiores. Porém, as partículas inaláveis finas, chamadas de $\mathrm{MP}_{2,5}$ (partículas com o diâmetro inferior a 2,5 $\mu \mathrm{m}$ ), por chegarem a trato respiratório inferior e penetrarem na corrente sanguínea podem provocar milhões de mortes todos os anos (SEINFELD; PANDIS, 2016).

Ao longo dos anos foram ocorrendo diversos eventos, como paralisações, greves, jogos olímpicos, que causaram alterações na qualidade do ar. Por exemplo, no ano de 2010 em Guangzhou (China), aconteceram os jogos asiáticos, um evento multiesportivo realizado na Ásia a cada quatro anos. Durante o período do evento, Lin et al. (2014) notaram a redução na concentração de $\mathrm{MP}_{10}$, em comparação ao mesmo período de anos anteriores, o que pode ter contribuído com a redução do número de mortes diárias por doenças não acidentais, cardiovasculares e respiratórias.

Também existiram, no Brasil, eventos que alteraram a qualidade do ar. Observou-se que, durante o período de paralisação do sistema de metrô da cidade de São Paulo, houve um agravamento da qualidade do ar, sendo que, nos dias de greve, foi possível notar o aumento do tráfego de veículos individuais, ocasionando impactos na saúde da população, com a maior produção de poluentes atmosféricos (SILVA et al., 2012). Dantas et al. (2019) analisaram a concentração de poluentes atmosféricos durante uma greve nacional, em 2018, realizada por caminhoneiros, em função ao aumento do preço do diesel. Durante o período de greve, os postos de gasolina ficaram sem combustível e como consequência houve a redução do tráfego de veículos, e a redução da concentração de outros poluentes primários, na cidade do Rio de Janeiro. 
O surto da doença COVID-19, causada pela síndrome respiratória aguda grave do coronavírus 2 (SARS-Cov-2), iniciou na China e teve o monitoramento de governos, pesquisadores e o público (WANG et al., 2020). Este surto foi declarado pela OMS, em 31/01/2020, como emergência de Saúde Pública de Interesse Internacional e, posteriormente (11/03/2020), foi classificado como uma pandemia (MAIER e BROCKMANN, 2020). Foram implementadas várias estratégias para evitar a propagação da epidemia, como medidas de distanciamento social com redução das atividades econômicas, com a paralisação de empresas e negócios não essenciais à população visando a proteção. Outra estratégia, adotada por alguns países, foi a imposição do toque de recolher obrigatório (BRISCESE et al., 2020; MAIER; BROCKMANN, 2020).

A poluição atmosférica pode estar relacionada à propagação de vírus (LIU et al., 2020; THE GUARDIAN, 2020). Cui et al. (2003) já haviam realizado um estudo, na China, analisando o SARS, anterior ao COVID-19. Estes autores notaram que a taxa de mortalidade era mais alta nas regiões em que os níveis de poluição do ar eram moderados, quando comparado a outras regiões do país em que os níveis de poluição do ar eram baixos.

Pelo que foi apresentado, até hoje, não há como identificar como as pessoas são infectadas (CONTINI; COSTABILE, 2020). Existem diferentes formas de transmissão entre os humanos, como o contato direto entre pessoas infectadas e suscetíveis ou o contato indireto por meio de um objeto ou superfície contaminada pelo vírus. Também existe a contaminação aérea com dois modos distintos. O primeiro é liberado pelo indivíduo através da tosse ou espirro, é caracterizado por grandes gotículas carregadas de vírus. O segundo modo é quando a pessoa inala pequenos aerossóis carregados de vírus que são liberados pela respiração (ASADI et al., 2020). As grandes gotículas são interrompidas pela resistência do ar e sedimentação gravitacional, porém, os pequenos aerossóis provenientes da emissão respiratória podem permanecer no ar por horas e podem ser dispersas com 0 vento (ANDERSON et al., 2020). Logo, é possível que esse último mecanismo possa contribuir para a proliferação do vírus (JAYAWEERA et al., 2020).

Para poder controlar o surto de coronavírus na China foram adotadas diversas medidas de restrição de tráfego em Wuhan, cidade que foi o epicentro da doença, se estendendo depois para outras províncias chinesas (YUAN et al., 2020). Devido às medidas impostas pela China, houve melhorias da qualidade do ar e que trouxeram benefícios à saúde humana em relação a mortes não relacionadas ao vírus, o que poderia superar em número as mortes atribuídas ao COVID-19 no país (ISAIFAN, 2020). Wu et al., 2020, em 
mais de 3 mil municípios dos Estados Unidos, descobriram que altos níveis de $\mathrm{MP}_{2,5}$ estavam associados a maiores taxas de mortalidade pela doença. Os resultados desta pesquisa mostram que a exposição a longo prazo à poluição atmosférica pode aumentar a vulnerabilidade das pessoas, agravando os quadros da doença.

Em 16/03/2020, foi declarado estado de emergência de saúde pública na cidade do Rio de Janeiro devido ao surgimento da COVID-19 e foram tomadas medidas parciais de bloqueio. O estudo, realizado por Dantas et al. (2020), analisou concentrações de poluentes atmosféricos, notando que os níveis de concentração de $\mathrm{CO}$ apresentaram reduções mais significativas por estarem relacionados a emissões de veículos. No entanto, a redução durou apenas algumas semanas, já que foi observado um aumento no tráfego de veículos como consequência da falta de consenso sobre a importância do distanciamento social.

As principais medidas tomadas para conter o vírus Sars-CoV-2 foram: o isolamento de casos, rastreamento de contatos, bloqueio e distanciamento social (TAVELLA; SILVA, 2020). Sendo assim, segundo Lin et al. (2014), a redução na concentração de poluentes atmosféricos consequentemente reduz a taxa de mortalidade por doenças não acidentais, cardiovasculares e respiratórias, mostrando a importância da redução da poluição do ar para melhorar a saúde pública. Com isso, é importante que seja feita uma análise sobre a quarentena imposta pelas autoridades com a finalidade de conter a proliferação da doença, para verificar a influência do vírus em relação à qualidade do ar, uma vez que foram adotadas ações de contenção a fim de reduzir os efeitos da pandemia (DANTAS et al., 2020).

Este artigo teve como objetivo verificar se houve redução de concentração de material particulado no município de Campinas (SP) devido às medidas de isolamento social tomadas. Além disso, comparamos as concentrações durante as diferentes fases de restrições impostas pelo governo para a contenção do coronavírus.

\section{METODOLOGIA}

\section{1 Área de Estudo}

Campinas é uma cidade do interior do estado de São Paulo com área de $801 \mathrm{~km}^{2} \mathrm{e}$ localizada a $100 \mathrm{~km}$ a noroeste da capital do estado. Possui população de aproximadamente 1,2 milhões de habitantes (IBGE, 2020) que é distribuída dentro de seus 4 distritos e centenas de bairros (CAMPINAS, 2020a). É classificado como o terceiro 
município mais populoso do estado de São Paulo e se destaca por ser classificado em quinto lugar entre as 100 melhores e maiores cidades brasileiras (DELTA, 2015). Atualmente, sua principal fonte de renda tem como base a indústria, o comércio e a agricultura, sendo a décima cidade mais rica do Brasil e é responsável por mais de 15\% de toda a produção científica do país (CAMPINAS, 2020b). Também se destaca por possuir um moderno parque industrial e tecnológico (IBGE, 2020).

\subsection{Aquisição de Dados e Detalhamento dos Locais de Amostragem}

Foram usados dados de concentração $\left(\mu \mathrm{g} / \mathrm{m}^{3}\right)$ de $\mathrm{MP}_{10}, \mathrm{MP}_{2,5}$ do município de Campinas, disponíveis na plataforma online de qualidade do ar (QUALAR, 2020) no site da Companhia Ambiental do Estado de São Paulo (CETESB). A CETESB possui uma rede de monitoramento da qualidade do ar composta por todas as estações automáticas do estado de São Paulo. Cada estação possui uma representatividade espacial distinta que determina a área de interesse no entorno da estação que indica concentrações uniformes e similares aos resultados avaliados na estação (CETESB, 2016). Campinas possui três estações automáticas de monitoramento da qualidade do ar (Figura 1), responsáveis por realizarem o acompanhamento da concentração de substâncias presentes nas emissões provenientes de fontes, como a circulação de veículos e indústrias.

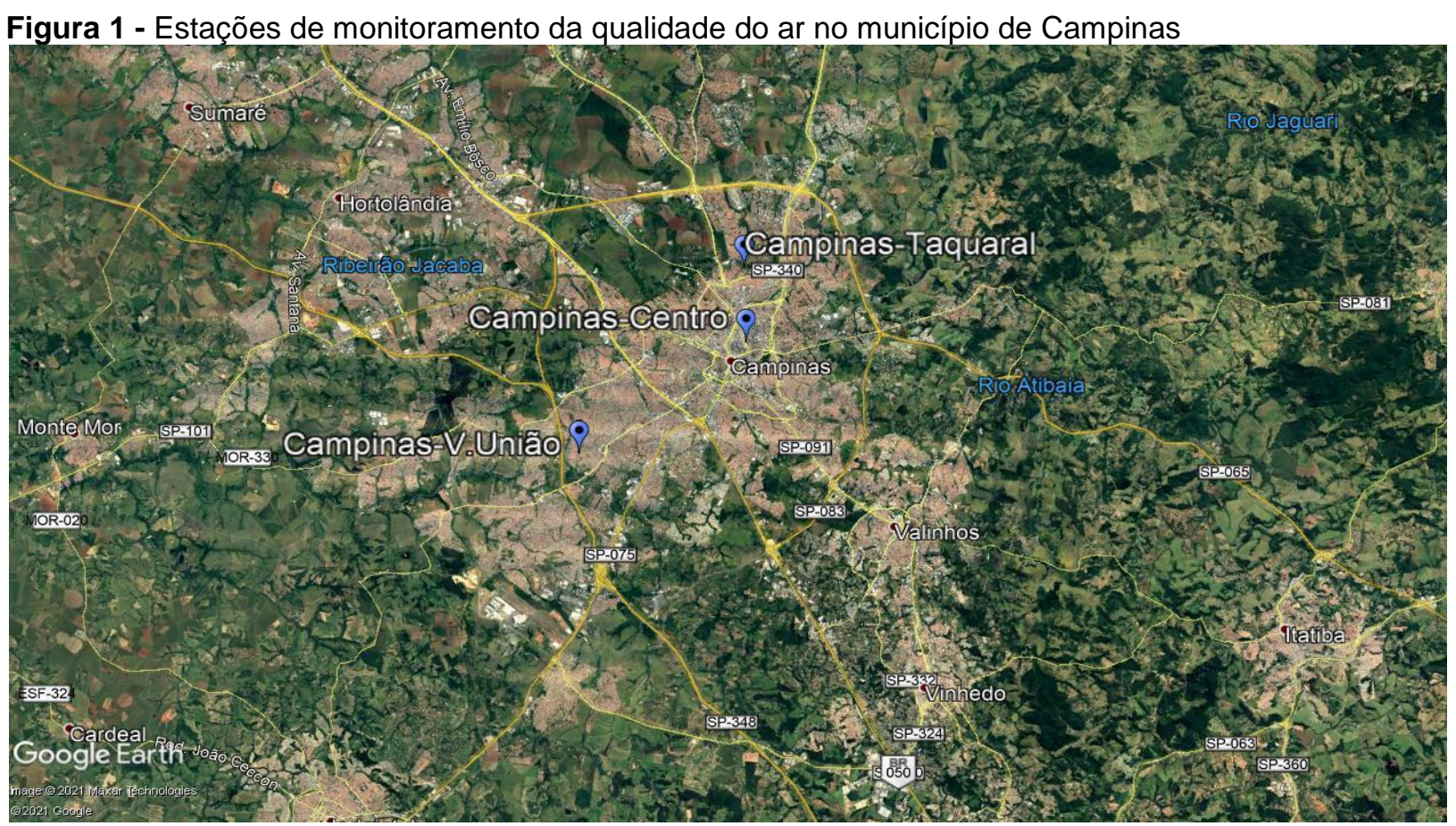

Fonte: Google Earth (2021) 


\subsubsection{Estação Campinas-Centro}

A estação de monitoramento Campinas-Centro (C-C) está localizada no centro de Campinas, região que possui grande parte do comércio e de serviços do município. Nesta estação, para as análises deste estudo, foram utilizados os dados horários da concentração de $\mathrm{MP}_{10}$ de 01/ 2019 a 12/2020. A estação C-C (Figura 2) possui classificação espacial de microescala (áreas de dimensão de poucos metros até $100 \mathrm{~m}$ ), representado apenas pela região do bairro onde está localizada, podendo ser coletados dados relacionados principalmente a emissões por tráfegos de veículos e serviços locais (CETESB, 2016).

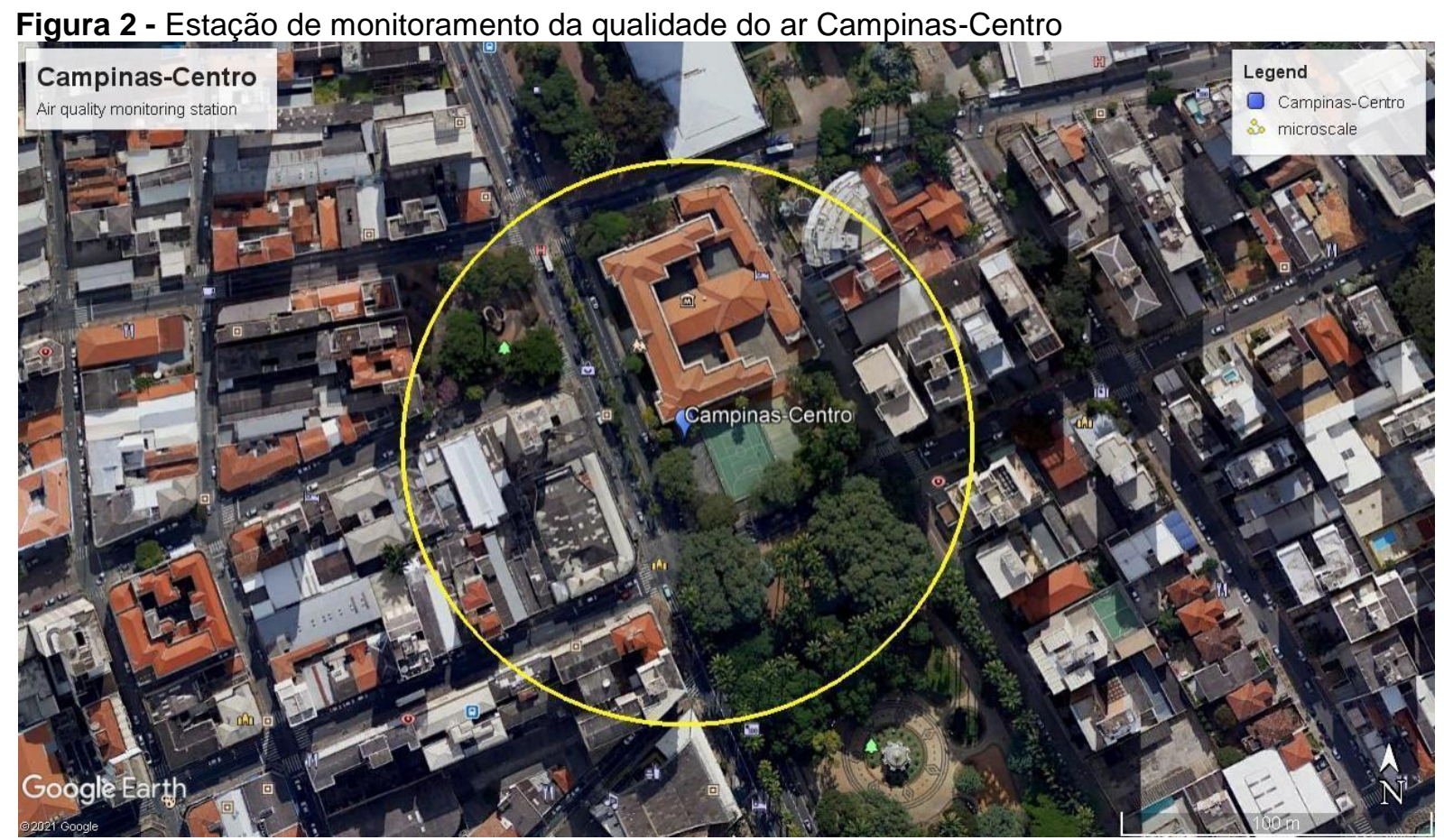

Fonte: Google Earth (2021)

\subsubsection{Estação Campinas-Taquaral}

A estação de monitoramento Campinas-Taquaral (C-T) fica no bairro Taquaral, na região leste, considerado um dos bairros mais tradicionais de Campinas (CAMPINAS, 2020a). Na estação C-T foram utilizados os dados horários da concentração de MP 10 de 01/2019 a 12/2020 (QUALAR, 2020). A estação C-T (Figura 3) possui classificação espacial de escala de bairro (áreas de dimensões entre 501 e 4.000 m), representado por uma área extensa de toda a cidade, podendo ser relacionados a emissões industriais, agrícolas, tráfegos de veículos e serviços de modo geral (CETESB, 2016). 
Figura 3 - Estação de monitoramento da qualidade do ar Campinas-Taquaral

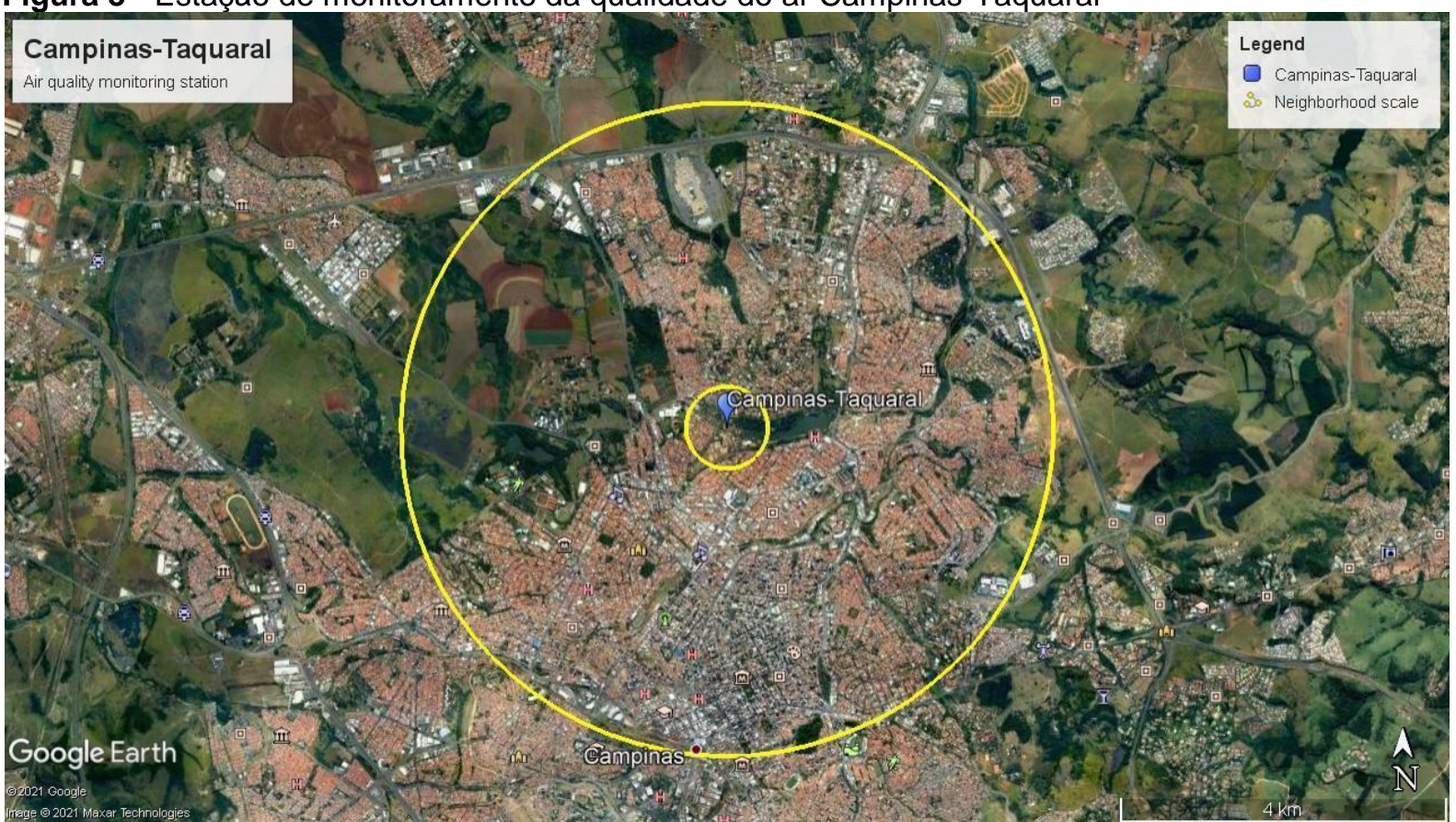

Fonte: Google Earth (2021)

\subsubsection{Estação Campinas-Vila União}

A estação de monitoramento Campinas-V.União (C-VU) fica no Parque Residencial Vila União, na região sudoeste, próximo à Rodovia dos Bandeirantes ${ }^{2}$. Na estação C-VU foram utilizados os dados horários de concentração de MP $_{2,5}$ entre 01/2019 e 12/2020 (QUALAR, 2020). A estação C-VU (Figura 4) possui classificação espacial de escala urbana (áreas de dimensões entre 4 e $50 \mathrm{~km}$ ), representado por uma área bastante extensa, incluindo cidades vizinhas. Sendo assim, podem ser coletados dados relacionados a emissões industriais, agrícolas, tráfego de veículos e até contribuições de emissões regionais (CETESB, 2016).

\footnotetext{
${ }^{2}$ Rodovia dos Bandeirantes (SP-348) é uma das mais importantes rodovias do país.
} 
Figura 4 - Estação de monitoramento da qualidade do ar Campinas-V.União

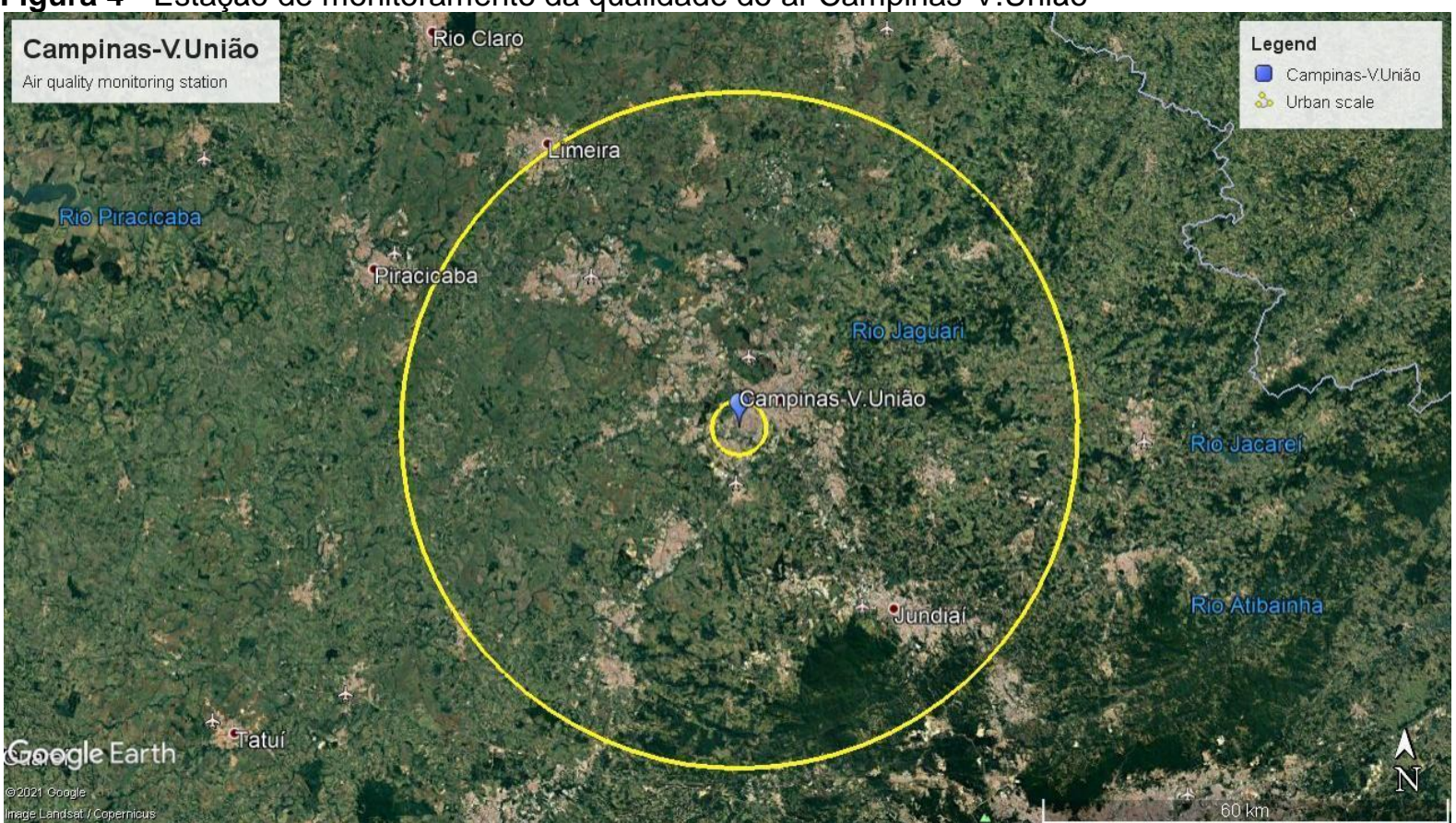

Fonte: Google Earth (2021)

\subsection{Taxas de Isolamento Social}

Foram usadas as taxas de isolamento social (Tabela 1), publicados pelo site do governo do estado de São Paulo (SÃO PAULO, 2020a) que ficaram disponíveis a partir do dia 05/03/2020. Essa taxa é calculada a partir de dados fornecidos pelas operadoras de telefonia celular, com informações sobre o deslocamento da população. No período avaliado a cidade de Campinas apresentou valores de isolamento social, mínimos e máximos, respectivamente, entre $26 \%$ e $59 \%$. Porém, as marcas permaneceram fora da meta de contingência do vírus, que foi definida como, ao menos, 70\%. Sendo assim, Campinas apresenta uma média total de aproximadamente $43 \%$.

Tabela 1 - Média mensal da taxa de isolamento social de Campinas, entre 03/2020 e 12/2020

$\stackrel{\&}{\Perp}$ Mar Abr Mai Jun Jul Ago Set Out Nov Dez Média

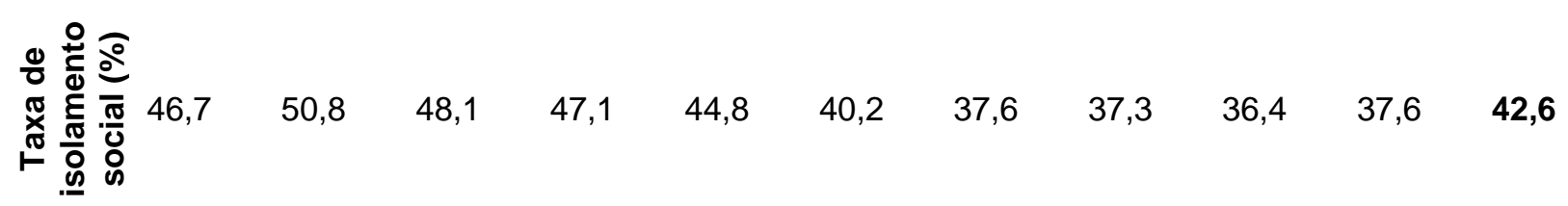




\subsection{Etapas de Quarentena}

Devido a proliferação do vírus no Brasil, diversas autoridades locais começaram a tomar medidas para evitar a aglomeração de pessoas com o intuito de diminuir o número de contaminados. O Decreto Estadual № 64.881 (SÃO PAULO, 2020b) determinou o início da quarentena em todos os municípios do estado de São Paulo em 24/03/2020. Posteriormente, a cidade de Campinas publicou um Decreto Municipal № 20.956 (CAMPINAS, 2020c) prorrogando o período de quarentena por tempo indeterminado.

Figura 5 - Fases do plano "Retomada consciente" do estado de São Paulo

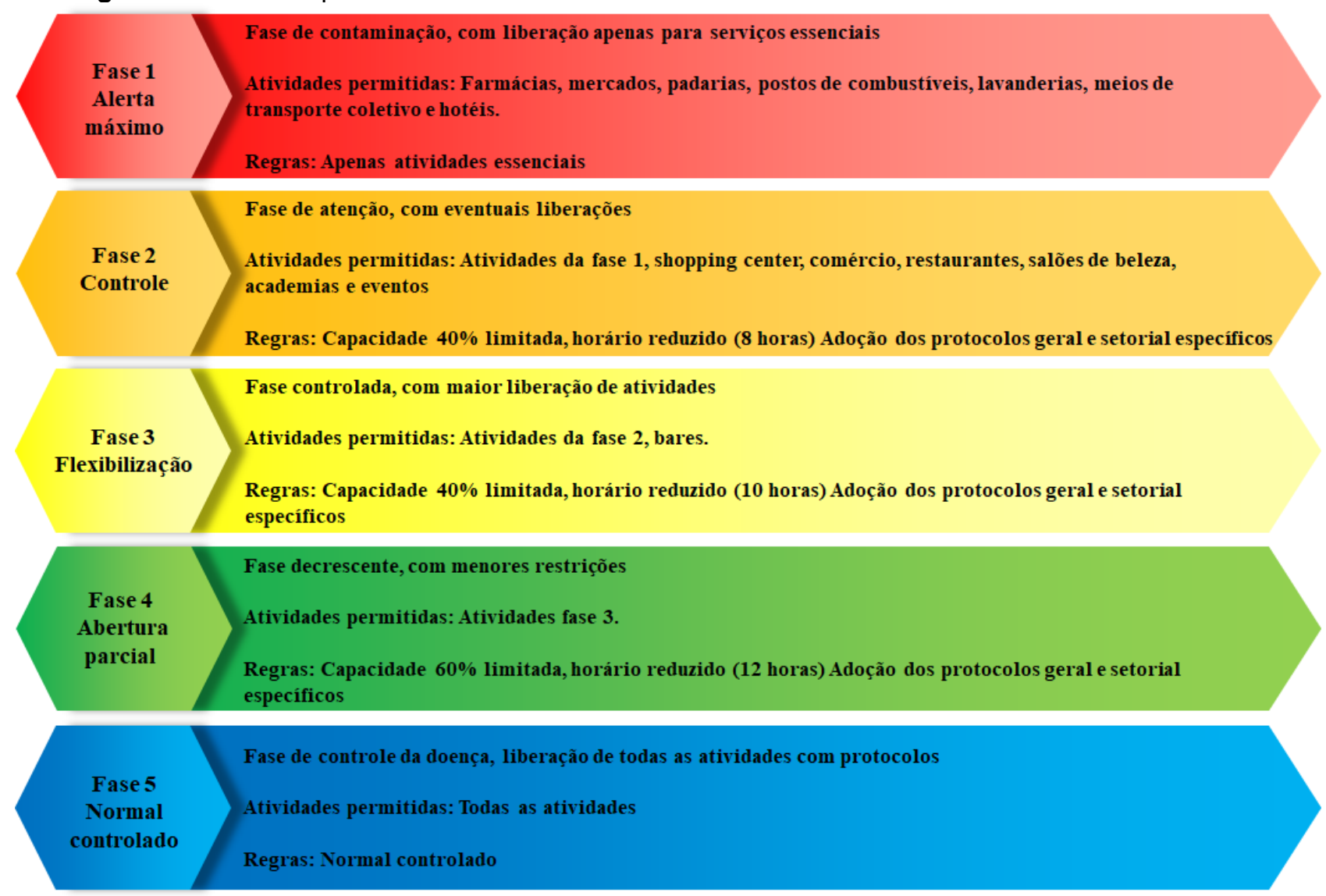

Fonte: São Paulo (2020d)

Com a publicação do Decreto Estadual № 64.994 (SÃO PAULO, 2020c), entrou em vigor no dia 01/06/2020 o plano conhecido como "retomada consciente". Esse plano consiste em classificar as cidades do estado de São Paulo em 5 fases (Figura 5), começando do alerta máximo até o novo normal controlado. Inicialmente o município de Campinas foi classificado na fase 2 (laranja) que permitiu a abertura de algumas atividades não essenciais com restrição de fluxo de pessoas e horários pré-definidos. 
Para uma cidade avançar entre as fases ela precisou ser avaliada periodicamente de acordo com os indicadores de saúde. Também existia a possibilidade de retrocesso de fase, caso os indicadores piorassem.

Durante esse período analisado, Campinas passou por diferentes fases. Essas fases foram definidas conforme a linha do tempo apresentada na Figura 6. Cabe salientar que 0 dia 31/12/2020 não representa o final da fase amarela, mas sim o último dia dos dados usados para este estudo.

Figura 6 - Fases da quarentena na cidade de Campinas

\begin{tabular}{|c|c|c|c|c|c|c|}
\hline$\cdot 28 / 05 / 2020$ & & • 24/07/2020 & & • 09/10/2020 & & $\cdot 31 / 12 / 2020$ \\
\hline - Laranja & Vermelha & Laranja & - Amarela & Verde & Amarela & - \\
\hline
\end{tabular}

\subsection{Tratamento de Dados}

Para uma primeira análise, comparou-se os meses dos anos de 2019 e 2020 utilizando a média de concentrações dos dados coletados de $\mathrm{MP}_{10}$ e $\mathrm{MP}_{2,5}$. Uma segunda análise dos dados foi realizada por meio de uma regressão linear, que objetiva verificar a existência de relações entre duas ou mais variáveis independentes (WEISBERG, 2005). Na regressão linear é calculada uma reta para relacionar os dados de dispersão da amostra. A partir da reta, obtém-se uma equação no formato $y=a x+b$, sendo " $\mathrm{x}$ " uma variável independente e "y" uma variável dependente, uma vez que y depende de $\mathrm{x}$. Os coeficientes "a" e "b" são obtidos por meio do método dos mínimos quadrados ordinários (CHARNET et al., 2008; WEISBERG, 2005). Nesta análise, as concentrações do MP foram consideradas variáveis dependentes, e a taxa de isolamento social foi a variável independente. A análise teve como base a identificação da existência da relação entre a diminuição das concentrações de poluentes no ar com o aumento da taxa de isolamento social. Nesta etapa também foram calculadas as correlações entre as concentrações do MP e a taxa de isolamento.

Uma terceira análise foi realizada a fim de identificar a variação da concentração de material particulado entre as 5 diferentes fases do em que Campinas foi classificada durante o ano. 


\section{RESULTADOS E DISCUSSÃO}

\subsection{Comparação da Concentração de MP entre os Anos 2019 e 2020}

Conforme já reportado por Nogarotto, Rissi e Pozza (2019), na base do Qualar (QUALAR, 2020) há lacunas de dados de concentração do MP que podem prejudicar a qualidade das amostras. Na estação C-C foram utilizados os dados de 701 dias de um total de 730 , o que representa $96 \%$ da amostragem. Assim, durante o período de estudo, verificou-se uma diminuição das concentrações de $\mathrm{MP}_{10}$ no ano de 2020 em comparação com a concentração do ano anterior (Tabela 2), de aproximadamente 4\%. Nota-se que na maioria dos meses durante a fase de quarentena, as concentrações ficaram menores em 2020, do que em 2019.

No mês de março foi observado um aumento que pode ser justificado por ter sido o mês em que foi decretado o período de quarentena, ou seja, na primeira metade do mês todas as atividades continuaram em funcionamento. Também houve um aumento da concentração em setembro e outubro (Tabela 2), sendo um dos possíveis motivos a menor adesão da população ao isolamento social, já que muitas atividades voltaram ao normal na cidade e a taxa de isolamento tem se tornado cada vez menor (Tabela 1). Outro possível motivo do aumento na concentração de $\mathrm{MP}_{10}$ pode ser a condição climática do período, uma vez que foi caracterizado como o período mais seco desde 1989, ocasionando maior número de queimadas na região de Campinas (INPE, 2020).

$\mathrm{Na}$ estação C-T foram utilizados os dados de 616 dias de um total de 730, o que representa $84 \%$ da amostragem. Sendo que no mês de abril não foi possível obter dados, uma vez que não estavam disponíveis. De modo geral (Tabela 3), não houve alteração na concentração de $\mathrm{MP}_{10}$ na estação $\mathrm{C}-\mathrm{T}$, uma vez que a variação é menor que $1 \%$ em todo o período analisado devido à grande alteração no mês de setembro de 2020. Porém, vale ressaltar que a concentração média de setembro foi que auxiliou no valor da média geral de 2020, já que a maioria dos meses apresentaram queda em relação a 2019. Ao ser analisado a média total desconsiderando o mês de setembro, o valor seria de $21,18 \mu \mathrm{g} / \mathrm{m}^{3}$ no ano de 2019 em comparação a 19,77 $\mu \mathrm{g} / \mathrm{m}^{3}$ para 2020. Ou seja, haveria redução média total de aproximadamente $7 \%$ de $\mathrm{MP}_{10}$. 
Tabela 2 - Média mensal da concentração $\left(\mu \mathrm{g} / \mathrm{m}^{3}\right)$ de $\mathrm{MP}_{10}$ na estação C-C e a variação $(\Delta)$ entre os anos 2019 e 2020

\begin{tabular}{|c|c|c|c|c|}
\hline \multirow[t]{2}{*}{ Mês } & \multicolumn{2}{|c|}{$\mathrm{MP}_{10}\left(\mu \mathrm{g} / \mathrm{m}^{3}\right)$} & \multicolumn{2}{|c|}{$\Delta$} \\
\hline & 2019 & 2020 & (\%) & $\left(\mu \mathrm{g} / \mathrm{m}^{3}\right)$ \\
\hline Janeiro & 21,48 & 17,82 & $-17,02$ & $-3,66$ \\
\hline Fevereiro & 19,40 & 18,91 & $-2,49$ & $-0,48$ \\
\hline Março & 19,71 & 21,24 & 7,81 & 1,54 \\
\hline Abril & 23,95 & 22,59 & $-5,67$ & $-1,36$ \\
\hline Maio & 25,94 & 24,81 & $-4,37$ & $-1,13$ \\
\hline Junho & 27,24 & 22,49 & $-17,43$ & $-4,75$ \\
\hline Julho & 29,61 & 27,09 & $-8,48$ & $-2,51$ \\
\hline Agosto & 28,57 & 26,31 & $-7,90$ & $-2,26$ \\
\hline Setembro & 35,87 & 38,80 & 8,15 & 2,92 \\
\hline Outubro & 27,49 & 29,08 & 5,77 & 1,59 \\
\hline Novembro & 21,11 & 20,42 & $-3,28$ & $-0,69$ \\
\hline Dezembro & 17,29 & 16,50 & $-4,57$ & $-0,79$ \\
\hline Média & 24,80 & 23,84 & $-3,89$ & $-0,96$ \\
\hline
\end{tabular}

Tabela 3 - Média mensal da concentração $\left(\mu \mathrm{g} / \mathrm{m}^{3}\right)$ de $\mathrm{MP}_{10}$ na estação C-T e a variação $(\Delta)$ entre os anos 2019 e 2020

\begin{tabular}{|c|c|c|c|c|}
\hline \multirow[t]{2}{*}{ Mês } & \multicolumn{2}{|c|}{$M P_{10}\left(\mu \mathrm{g} / \mathrm{m}^{3}\right)$} & \multicolumn{2}{|c|}{$\Delta$} \\
\hline & 2019 & 2020 & (\%) & $\left(\mu \mathrm{g} / \mathrm{m}^{3}\right)$ \\
\hline Janeiro & 17,42 & 13,63 & $-21,76$ & $-3,79$ \\
\hline Fevereiro & 14,67 & 11,08 & $-24,46$ & $-3,59$ \\
\hline Março & 20,27 & 16,20 & $-20,08$ & $-4,07$ \\
\hline Abril & 19,91 & & & \\
\hline Maio & 21,68 & 21,27 & $-1,88$ & $-0,41$ \\
\hline Junho & 24,56 & 21,86 & $-10,98$ & $-2,70$ \\
\hline Julho & 27,67 & 27,16 & $-1,85$ & $-0,51$ \\
\hline Agosto & 26,77 & 26,39 & $-1,40$ & $-0,37$ \\
\hline Setembro & 30,75 & 44,74 & 45,51 & 13,99 \\
\hline Outubro & 26,17 & 28,17 & 7,62 & 1,99 \\
\hline Novembro & 16,92 & 17,91 & 5,85 & 0,99 \\
\hline
\end{tabular}


Tabela 3 - Média mensal da concentração $\left(\mu \mathrm{g} / \mathrm{m}^{3}\right)$ de $\mathrm{MP}_{10}$ na estação C-T e a variação $(\Delta)$ entre os anos 2019 e 2020

(conclusão)

\begin{tabular}{cccccc|}
\hline Mês & \multicolumn{2}{c}{ MP $_{10}\left(\mu \mathrm{g} / \mathbf{m}^{3}\right)$} & \multicolumn{2}{c}{$\Delta$} \\
\cline { 2 - 6 } & $\mathbf{2 0 1 9}$ & $\mathbf{2 0 2 0}$ & $(\%)$ & $\left(\boldsymbol{\mu g} / \mathbf{m}^{3}\right)$ \\
\cline { 2 - 6 } Dezembro & 15,63 & 14,06 & $-10,05$ & $-1,57$ \\
Média* $^{n}$ & $\mathbf{2 2 , 0 5}$ & $\mathbf{2 2 , 0 4}$ & $-\mathbf{0 , 0 1}$ & $\mathbf{0 , 0 0}$ \\
\hline
\end{tabular}

* Média calculada apenas com os meses que possuem dados nos anos de 2019 e 2020.

Já na estação de monitoramento C-VU, de modo geral, foi possível identificar uma diminuição na média de concentração de $\mathrm{MP}_{2,5}$ em aproximadamente 16\% (Tabela 4). Sendo que dos 730 dias totais, apenas 506 dias foram usados para a base de cálculo, o que representa $69 \%$ da amostra.

A estação de monitoramento C-VU apresentou uma alta redução da concentração de $\mathrm{MP}_{2,5}$ (Tabela 4) que pode ser associada também a sua maior área de influência. Essa estação é classificada como de escala urbana e pode ser influenciada por cidades vizinhas.

Tabela 4 - Média mensal da concentração $\left(\mu \mathrm{g} / \mathrm{m}^{3}\right)$ de $\mathrm{MP}_{2,5}$ na estação C-VU e a variação $(\Delta)$ entre os anos 2019 e 2020

\begin{tabular}{|c|c|c|c|c|}
\hline \multirow[t]{2}{*}{ Mês } & \multicolumn{2}{|c|}{$\mathrm{MP}_{2,5}\left(\mu \mathrm{g} / \mathrm{m}^{3}\right)$} & \multicolumn{2}{|c|}{$\Delta$} \\
\hline & 2019 & 2020 & (\%) & $\left(\mu \mathrm{g} / \mathrm{m}^{3}\right)$ \\
\hline Janeiro & 12,79 & 11,03 & $-13,75$ & $-1,76$ \\
\hline Fevereiro & 10,17 & 8,32 & $-18,21$ & $-1,85$ \\
\hline Março & 10,26 & 11,87 & 15,71 & 1,61 \\
\hline Abril & 16,22 & 16,21 & $-0,03$ & $-0,01$ \\
\hline Maio & 24,59 & 19,29 & $-21,53$ & $-5,29$ \\
\hline Junho & 27,41 & & & \\
\hline Julho & 26,18 & & & \\
\hline Agosto & 24,25 & & & \\
\hline Setembro & 26,83 & & & \\
\hline Outubro & 24,33 & & & \\
\hline Novembro & 16,50 & 12,42 & $-24,74$ & $-4,08$ \\
\hline Dezembro & 14,74 & 9,33 & $-36,69$ & $-5,41$ \\
\hline Média** & 15,04 & 12,64 & $-15,95$ & $-2,40$ \\
\hline
\end{tabular}

* Os dados de junho a outubro não estão disponíveis na Plataforma QUALAR.

** Média calculada apenas com os meses que possuem dados nos anos de 2019 e 2020. 
De modo geral, as concentrações de $\mathrm{MP}_{10}$ e $\mathrm{MP}_{2,5}$ apresentaram redução na concentração do ano de 2020 em relação ao ano anterior. Como Siciliano et al. (2020) apontaram, a diminuição de poluentes não foi diretamente proporcional à redução do tráfego de veículos, pois existem outros fatores como parâmetros meteorológicos, transporte de massas de ar e outras fontes de emissão que interferem nas amostras analisadas.

A pequena variação dos níveis de $\mathrm{MP}_{10}$ (notada na estação C-T) pode estar relacionada à circulação de caminhões, atividades de construção civil, emissões industriais e ressuspensão de poeira que continuaram manifestando-se mesmo com a paralisação parcial da cidade de Campinas. Outro fator agravante, pode ser a baixa adesão da população devida à retomada de atividades na cidade, uma vez que a maior taxa de isolamento encontrada na cidade foi de $59 \%$, valor abaixo da meta de contingência do vírus que foi definida como 70\% (São Paulo, 2020c).

\subsection{Análise de Regressão Linear}

No estudo de regressão linear as amostras foram separadas a partir do dia em que foi iniciado o monitoramento da taxa de isolamento social de Campinas, dia 05/03/2020 até o dia 31/12/2020. Além disso, foram selecionados apenas os dias que possuíam as duas bases de cálculos: a concentração de material particulado e a taxa de isolamento social.

Para a estação C-C foram utilizados 282 dias do total de 306 , o que representa $92 \%$ das amostras. A Figura 7 mostra os resultados estimados pela análise de regressão. Com isso, foi possível observar que a cada ponto percentual (p.p.) de aumento na taxa de isolamento social houve redução na concentração de material particulado, ou seja, para cada 1 p.p. de aumento na taxa de isolamento social na cidade há um decréscimo médio de cerca de $0,31 \mu \mathrm{g} / \mathrm{m}^{3}$ de $\mathrm{MP}_{10}$. Essa relação é considerada significativa ao nível de $1 \%$ conforme observado na Tabela 5.

Para a estação de monitoramento C-T foram utilizados 220 dias do total de 306, o que representa $72 \%$ das amostras. Na Figura 8 e Tabela 6 são apresentados o gráfico de dispersão da concentração do MP e a taxa de isolamento, além da equação de regressão e sua significância.

Neste caso, para cada 1 p.p. de aumento na taxa de isolamento social na cidade há um decréscimo médio de $0,50 \mu \mathrm{g} / \mathrm{m}^{3}$ de $\mathrm{MP}_{10}$. Essa relação é significativa ao nível de $1 \%$ (Tabela 6). 
Figura 7 - Relação entre as concentrações de $\mathrm{MP}_{10}$ e a taxa de isolamento social da cidade de Campinas para C-C, durante o período de quarentena do COVID-19

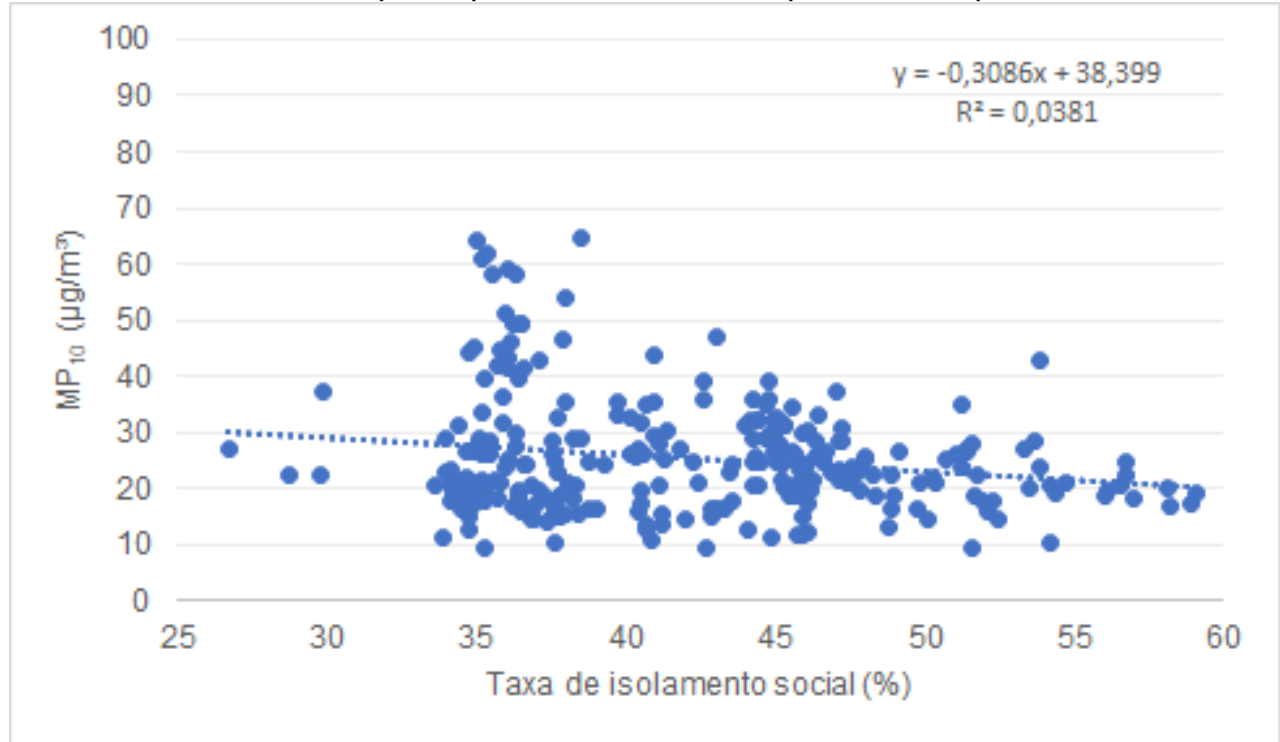

Tabela 5 - Resultados da análise de regressão linear para C-C

\begin{tabular}{|c|c|c|}
\hline \multicolumn{1}{c}{ Parâmetros } & \multicolumn{1}{c}{ Coeficiente } & \multicolumn{1}{c}{ p-valor } \\
\hline Intersecção & 38,399441 & $<0,00001^{* * *}$ \\
Taxa de Isolamento (\%) & $-0,308561$ & $0,000976^{* * *}$ \\
\hline$* *$ : significativa a 1\%. & &
\end{tabular}

Figura 8 - Relação entre as concentrações de $\mathrm{MP}_{10}$ e a taxa de isolamento social da cidade de Campinas para C-T, durante o período de quarentena do COVID-19

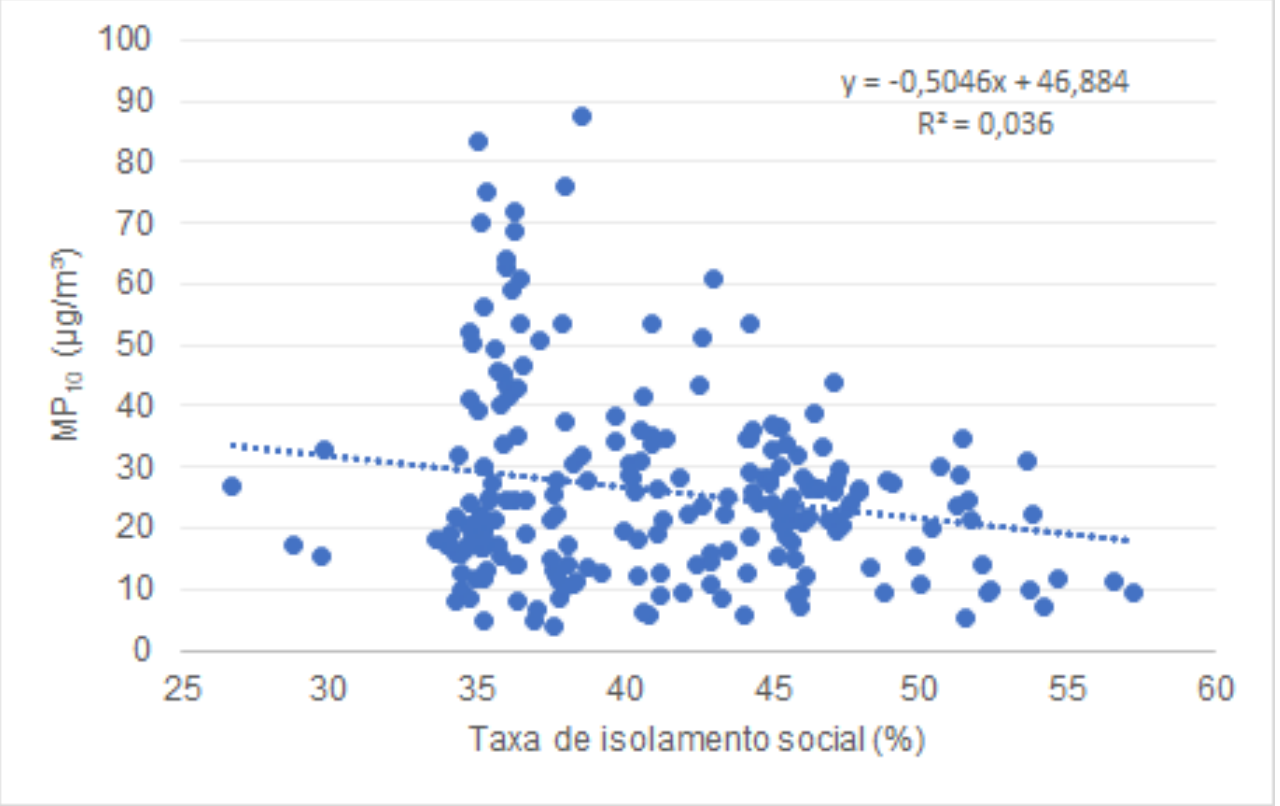


Tabela 6 - Resultados da análise de regressão linear para C-T

\begin{tabular}{|cc|c|}
\hline Parâmetros & Coeficiente & p-valor \\
\hline Intersecção & 46,883773 & $<0,00001^{* * *}$ \\
Taxa de Isolamento (\%) & $-0,504647$ & $0,004748^{* * *}$ \\
\hline$* * *$ significativa a 1\%. & &
\end{tabular}

Já para C-VU foram utilizados apenas 131 dias do total de 306, o que representa apenas $43 \%$ das amostras. A Figura 9 apresenta o gráfico de dispersão dos dados de taxa de isolamento com a concentração do $\mathrm{MP}_{2,5}$ e a equação de regressão estimada possui outro comportamento se comparada às demais estações, a relação é diretamente proporcional. Ou seja, para cada 1 p.p. de aumento na taxa de isolamento social na cidade há um acréscimo médio de $0,16 \mu \mathrm{g} / \mathrm{m}^{3}$ de $\mathrm{MP}_{2,5}$. Essa relação é considerada significativa ao nível de 5\% (Tabela 7). Entretanto, esperava-se que o coeficiente angular fosse negativo. Isso pode ser justificado devido ao número de amostras utilizadas no cálculo ser inferior a metade dos dias do período. Também existe a possibilidade de os dados serem afetados devido à proximidade da estação de monitoramento com a Rodovia dos Bandeirantes que possui um tráfego diário alto de caminhões que continuaram circulando, uma vez que foram mantidas as atividades industriais e de construção, bem como o transporte de alimentos e cargas em geral (BRASIL, 2020).

Figura 9 - Relação entre as concentrações de $\mathrm{MP}_{2,5}$ e a taxa de isolamento social da cidade de Campinas para C-VU, durante o período de quarentena do COVID-19

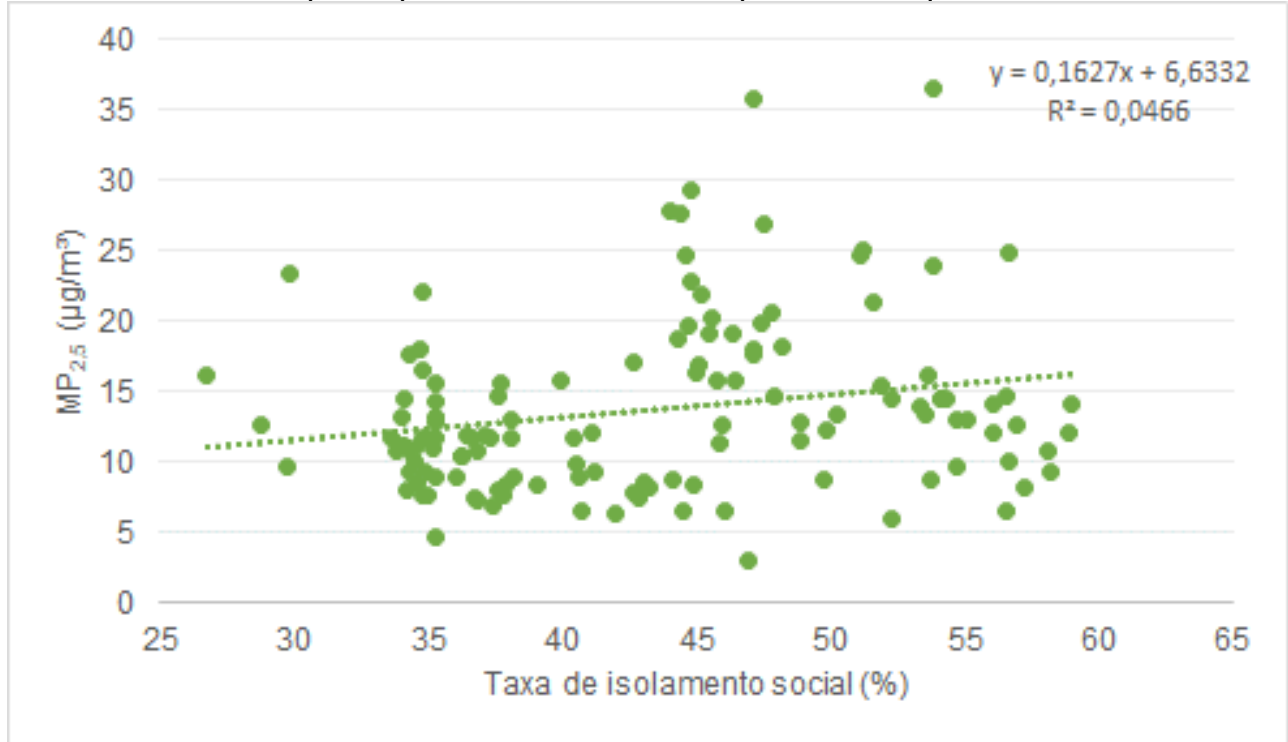


Segundo as Tabelas 5 e 6 foi possível constatar que existe uma relação entre a concentração de $\mathrm{MP}_{10}$ e a taxa de isolamento social. À medida que as pessoas evitavam sair de suas casas, por motivos não essenciais, a taxa de isolamento aumentou e a concentração de material particulado diminuiu. Ou seja, a correlação foi negativa nas estações de C-C $(-0,19531)$ e C-T $(-0,18972)$, conforme observado na Tabela 8. Por outro lado, na Tabela 8 , a relação da concentração do $\mathrm{MP}_{2,5}$ com a taxa de isolamento apresentou correlação positiva $(0,21597)$, isto é, o aumento da taxa de isolamento, levou ao aumento da concentração, conforme observado na análise de regressão (Tabela 7). Todas as correlações foram significativas, conforme observado na Tabela 8. Nota-se nas Figuras 7, 8 e 9 que os valores do $\mathrm{R}^{2}$ obtidos foram baixos, porém ficaram próximos aos encontrados por Noda et al. (2021), que também mediu a relação entre a concentração de poluentes atmosféricos com a taxa de isolamento social para a cidade de São Paulo.

Tabela 7 - Resultados da análise de regressão linear para C-VU

\begin{tabular}{|ccc|}
\hline \multicolumn{1}{c}{ Parâmetros } & Coeficiente & p-valor \\
\hline Intersecção & 6,633247 & $0,021707^{* *}$ \\
Taxa de Isolamento (\%) & 0,162662 & $0,013232^{* *}$ \\
\hline **: significativa a 5\%. &
\end{tabular}

Com o apresentado até aqui, podemos concluir que houve relação significativa entre a concentração do MP e a taxa de isolamento, porém essa correlação foi fraca, como observado nos valores obtidos do $\mathrm{R}^{2}$ (Figuras 7, 8 e 9) e na correlação (Tabela 8).

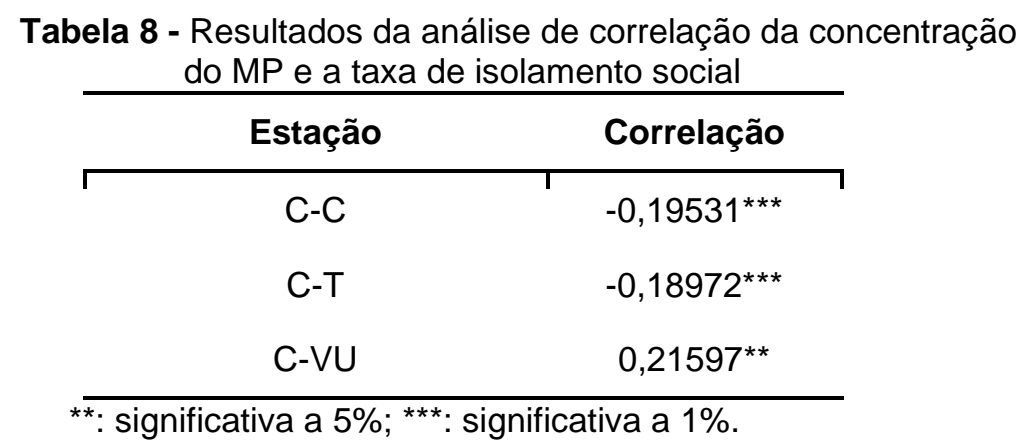

Alguns estudos realizados no Brasil já avaliaram a qualidade do ar durante o período da pandemia, ou seja, quando as medidas de isolamento social foram implementadas. A Tabela 9 apresenta os principais resultados obtidos desses estudos e compara com os obtidos neste trabalho. 
Tabela 9 - Comparação entre estudos brasileiros que analisaram a poluição atmosférica durante o isolamento social

\begin{tabular}{|c|c|c|c|c|c|}
\hline Autor (Ano) & $\begin{array}{c}\text { Poluente } \\
\text { atmosférico }\end{array}$ & Local & $\begin{array}{c}\text { Período } \\
\text { analisado da } \\
\text { Pandemia }\end{array}$ & $\begin{array}{c}\text { Análise } \\
\text { empregada }\end{array}$ & Conclusão \\
\hline Este estudo & $\mathrm{MP}_{10}$ & $\begin{array}{l}\text { Campinas } \\
\text { (Centro e } \\
\text { Taquaral) }\end{array}$ & $\begin{array}{c}03 / 2020- \\
12 / 2020\end{array}$ & $\begin{array}{l}\text { Análise de } \\
\text { regressão }\end{array}$ & $\begin{array}{l}\text { Redução da concentração } \\
\text { com aumento da taxa de } \\
\text { isolamento }\end{array}$ \\
\hline Este estudo & $\mathrm{MP}_{2,5}$ & $\begin{array}{l}\text { Campinas } \\
\text { (Vila União) }\end{array}$ & $\begin{array}{c}03 / 2020- \\
12 / 2020\end{array}$ & $\begin{array}{l}\text { Análise de } \\
\text { regressão }\end{array}$ & $\begin{array}{l}\text { Aumento da concentração } \\
\text { com o aumento da taxa de } \\
\text { isolamento }\end{array}$ \\
\hline $\begin{array}{c}\text { Dantas et al. } \\
2020\end{array}$ & $\begin{array}{l}\mathrm{MP}_{10}, \mathrm{NO}_{2} \\
\mathrm{CO}, \mathrm{O}_{3}, \mathrm{THC} \\
\mathrm{NMHC}\end{array}$ & Rio de Janeiro & $\begin{array}{c}03 / 2020- \\
04 / 2020\end{array}$ & $\begin{array}{l}\text { Variação na } \\
\text { concentração } \\
\text { mediana }\end{array}$ & $\begin{array}{c}\text { Redução na concentração } \\
\text { do } \mathrm{MP}_{10}, \mathrm{NO}_{2} \text { e } \mathrm{CO} \text { e } \\
\text { aumento na concentração } \\
\text { do } \mathrm{O}_{3} \text { durante as medidas } \\
\text { de isolamento. } \\
\text { Reducão na concentracão }\end{array}$ \\
\hline $\begin{array}{l}\text { Nakada e } \\
\text { Urban } \\
(2020)\end{array}$ & $\begin{array}{c}\mathrm{MP}_{2,5}, \mathrm{M}_{10} \\
\mathrm{CO}, \mathrm{NO}, \mathrm{NO}_{2} \\
\mathrm{NO}_{x}, \mathrm{SO}_{2} \mathrm{e} \mathrm{O}_{3}\end{array}$ & $\begin{array}{l}\text { São Paulo e } \\
\text { Cubatão }\end{array}$ & $\begin{array}{l}02 / 2020- \\
04 / 2020\end{array}$ & $\begin{array}{l}\text { Variação na } \\
\text { concentração } \\
\text { média }\end{array}$ & $\begin{array}{c}\text { do } \mathrm{NO}, \mathrm{NO}_{2} \text { e } \mathrm{CO} \text { e } \\
\text { aumento na concentração } \\
\text { do } \mathrm{O}_{3} \text { durante as medidas } \\
\text { de isolamento. }\end{array}$ \\
\hline $\begin{array}{l}\text { Azevedo et } \\
\text { al. (2021) }\end{array}$ & $\mathrm{NO}_{2}$ e $\mathrm{AOD}$ & $\begin{array}{l}\text { Região } \\
\text { Nordeste }\end{array}$ & $\begin{array}{c}01 / 2020- \\
06 / 2020\end{array}$ & $\begin{array}{l}\text { Imagens de } \\
\text { satélites }\end{array}$ & $\begin{array}{c}\text { Redução na concentração } \\
\text { do } \mathrm{NO}_{2} \text { durante as } \\
\text { medidas de isolamento }\end{array}$ \\
\hline $\begin{array}{l}\text { Noda et al. } \\
(2021)\end{array}$ & $\begin{array}{l}\mathrm{MP}_{10}, \mathrm{MP}_{2,5} \\
\mathrm{NO}_{x}, \mathrm{NO}, \mathrm{NO}_{2} \\
\mathrm{SO}_{2} \text { e } \mathrm{CO}\end{array}$ & São Paulo-SP & $\begin{array}{c}03 / 2020- \\
07 / 2020\end{array}$ & $\begin{array}{c}\text { Correlação de } \\
\text { Pearson }\end{array}$ & $\begin{array}{l}\text { Impacto positivo na } \\
\text { qualidade do ar }(\mathrm{NO}, \mathrm{NO}, \\
\left.\mathrm{NO}_{2} \text { e } \mathrm{CO}\right) \text { durante as } \\
\text { medidas de isolamento }\end{array}$ \\
\hline $\begin{array}{l}\text { Rosse et al. } \\
\qquad(2021)\end{array}$ & $\mathrm{NO}$ e $\mathrm{NO}_{2}$ & São Paulo-SP & $\begin{array}{l}01 / 2020- \\
04 / 2020\end{array}$ & $\begin{array}{c}\text { Testes de } \\
\text { Mann-Kendall e } \\
\text { Pettitt }\end{array}$ & $\begin{array}{l}\text { Redução da concentração } \\
\text { durante as medidas de } \\
\text { isolamento }\end{array}$ \\
\hline
\end{tabular}

A maioria dos estudos comparados (Tabela 9) concluíram que houve melhora na qualidade do ar devido as medidas impostas de isolamento social. Noda et al. (2021) encontraram valores próximos de correlação e $\mathrm{R}^{2}$ aos obtidos neste estudo para a concentração do MP com a taxa de isolamento social. Dantas et al. (2020) observaram uma maior redução do MP durante as primeiras semanas de isolamento.

Nakada e Urban (2020) e Dantas et al. (2020) notaram aumento na concentração do $\mathrm{O}_{3}$, sendo esse fato associado a redução dos níveis dos óxidos de nitrogênio. Entretanto, o primeiro analisando os dados de São Paulo e Cubatão, e o segundo analisando os dados do Rio de Janeiro. Rosse et al. (2021) e Noda et al. (2021) chegaram a conclusões muito parecidas, usando técnicas diferentes e período diferente. O estudo de Azevedo et al. (2021) foi realizado fora da região Sudeste brasileira e considerou dados de AOD (Profundidade Óptica de Aerossol), sem encontrar relação significativa com essa variável, mas obtiveram relação significativa com o $\mathrm{NO}_{2}$. 


\subsection{Comparação do MP entre as fases da quarentena}

A quarentena em Campinas passou por 6 etapas diferentes, desde que começou a ser classificada em fases, de acordo com o grau de necessidade (Figura 4). Consequentemente, foi calculada a concentração média de material particulado em cada fase da quarentena junto com a taxa de isolamento social (Tabela 10).

Os resultados (Tabela 10) mostram que mesmo com a implementação de novas medidas para o retorno consciente de atividades não essenciais, não houve adesão da população de modo geral, obtendo uma taxa de isolamento muito baixa em comparação às metas estabelecidas pelo governo (São Paulo, 2020c).

$\mathrm{Na}$ fase amarela (etapa 4) é possível observar os maiores valores na concentração de $\mathrm{MP}_{10}$ em relação às demais fases. Um dos possíveis motivos pode ser a menor adesão da população ao isolamento social e a flexibilização maior da cidade e dos estabelecimentos, uma vez que a taxa de isolamento nesta etapa foi uma das menores. Outra possível justificativa se deve ao período de seca que a cidade enfrentou durante o ano de 2020 e o grande número de queimadas que aumentaram se comparado aos anos anteriores, principalmente no mês de setembro (INPE, 2020).

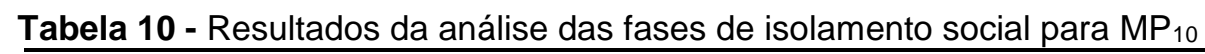

\begin{tabular}{|c|c|c|c|c|c|c|c|}
\hline Etapa & Início & Fim & $\begin{array}{l}\text { Total de } \\
\text { Dias }\end{array}$ & Fases & $\underset{\left(\mu \mathrm{g} / \mathrm{m}^{3}\right)}{\mathrm{C}-\mathrm{C}}$ & $\begin{array}{c}\text { C-T } \\
\left(\mu \mathrm{g} / \mathrm{m}^{3}\right)\end{array}$ & $\begin{array}{c}\text { Taxa de } \\
\text { isolamento } \\
\text { social (\%) }\end{array}$ \\
\hline 0 & $05 / 03 / 2020$ & $27 / 05 / 2020$ & 83 & $\begin{array}{l}\text { Não } \\
\text { definido }\end{array}$ & 23,55 & 17,56 & 48,32 \\
\hline 1 & $28 / 05 / 2020$ & $05 / 07 / 2020$ & 38 & Laranja & 23,01 & 22,73 & 47,28 \\
\hline 2 & 06/07/2020 & $23 / 07 / 2020$ & 17 & Vermelho & 29,26 & 29,23 & 45,14 \\
\hline 3 & $24 / 07 / 2020$ & 06/08/2020 & 13 & Laranja & 25,87 & 26,01 & 42,52 \\
\hline 4 & 07/08/2020 & 08/10/2020 & 62 & Amarelo & 34,31 & 37,97 & 38,35 \\
\hline 5 & 09/10/2020 & $30 / 11 / 2020$ & 52 & Verde & 22,39 & 19,29 & 36,98 \\
\hline 6 & $01 / 12 / 2020$ & $31 / 12 / 2020$ & 30 & Amarelo & 16,47 & 13,35 & 37,42 \\
\hline
\end{tabular}

Já os valores da fase verde (etapa 5) foram inesperados. Nota-se que nesta fase foi quando ocorreu a menor taxa de isolamento, mas ao mesmo tempo também foram as menores concentrações observadas. Por outro lado, Nakada e Urban (2020) observaram a diminuição na concentração de MP devido ao bloqueio parcial na cidade de São Paulo. 
Acredita-se que isso possa ter ocorrido, pois mesmo com a diminuição da taxa de isolamento social, houve aumento médio de chuvas na região de Campinas a partir do mês de outubro (CEPAGRI, 2020), ocasionando maior deposição de material particulado. $\mathrm{Na}$ última etapa analisada (6), retornando a fase amarela, os valores de concentração diminuíram devido a maior restrição imposta pelo governo, uma vez que houve agravamento do contágio do vírus devido ao início de uma segunda onda de transmissão. Apesar disso, as taxas de isolamento nesta etapa não foram tão altas quanto ao observado no início da pandemia.

\section{CONCLUSÃO}

Este estudo mostrou o impacto da paralisação imposta pela pandemia COVID-19 na qualidade do ar da cidade de Campinas, no ano de 2020. Os resultados apresentam evidências de que a concentração de material particulado pode ser afetada com a introdução das medidas de controle e distanciamento social, impostas pelos governos, que tiveram como finalidade de diminuir a propagação do vírus. Foram observadas mudanças de concentração de $\mathrm{MP}_{10}$ e $\mathrm{MP}_{2,5}$, porém a redução percentual foi relativamente pequena, comparada aos dados do mesmo período em 2019. Isso pode ser justificado pelo fato de que o material particulado é constituído por diversas fontes e não apenas relacionadas ao tráfego de veículos.

Também foi possível entender que houve relação fraca, mas significativa, entre as variáveis de concentração de $\mathrm{MP}_{10}$ e a taxa de isolamento social da cidade, ou seja, se as medidas de distanciamento social fossem mais efetivas, supostamente a redução da concentração do $\mathrm{MP}_{10}$ seria maior.

É importante compreender como é afetada a poluição do ar durante a pandemia de COVID-19 e como poderá fornecer dados importantes sobre os efeitos na saúde e o controle de emissões. Enquanto o mundo todo se preocupa com políticas adequadas para a redução da poluição ambiental, a paralisação devido ao novo coronavírus têm mostrado que uma melhor gestão da fonte de poluição pode auxiliar na restauração do meio ambiente e do ecossistema.

Uma análise futura pode ser feita para entender qual será o comportamento da concentração de material particulado após o período de pandemia. Além disso, a base de dados será maior, o que pode reduzir alguns erros encontrados devido à falta de amostras. 


\section{AGRADECIMENTOS}

Agradecemos à CETESB pela disponibilização, por meio da base de dados QUALAR (2020), dos dados de monitoramento dos poluentes atmosféricos, usados neste estudo.

\section{REFERÊNCIAS}

ANDERSON, E. L.; TURNHAM, P.; GRIFFIN, J. R.; CLARKE, C. C. Consideration of the Aerosol Transmission for COVID-19 and Public Health. Risk Analysis, v. 40, n. 5, p. 902-907, maio 2020. http://doi.org/10.1111/risa.13500

ASADI, S.; BOUVIER, N.; WEXLER, A. S.; RISTENPART, W. D. The coronavirus pandemic and aerosols: does covid-19 transmit via expiratory particles?. Aerosol Science And Technology, v. 54, n. 6, p. 635-638, 2020. http://doi.org/10.1080/02786826.2020.1749229

AZEVEDO, L. S.; CANDEIAS, A. L. B.; TAVARES JÚNIOR, J. R. Análise de mudanças na poluição atmosférica e sua relação com o isolamento social em função da pandemia da COVID-19 no Nordeste Brasileiro. Sociedade \& Natureza, v. 33, e59412, 2021. https://doi.org/10.14393/SNv33-2021-59412

BRASIL. Decreto № 10.282, de 20 de março de 2020. Diário Oficial da União, Brasília, 2020.

BRISCESE, G.; LACETERA, N.; MACIS, M.; TONIN, M. Expectations, reference points, and compliance with COVID-19 social distancing measures. The National Bureau of Economic Research, 2020. http://doi.org/10.3386/w26916

CAMPINAS. Campinas ganha terceira estação automática para monitorar qualidade do ar, 2015. Disponível em: http://www.campinas.sp.gov.br/noticias-integra.php?id=27082. Acesso em: 10 jun. 2020.

CAMPINAS. Dados do município, 2020a. Disponível em: http://www.campinas.sp.gov.br/sobrecampinas/campinas.php. Acesso em: 10 jun. 2020.

CAMPINAS. A cidade. 2020b.Disponível em:

http://www.campinas.sp.gov.br/governo/seplama/dados-do-municipio/cidade/. Acesso em: 10 ago. 2020.

CAMPINAS. Decreto № 20.956 de 6 de julho de 2020. Diário Oficial de Campinas, São Paulo, 2020c.

CEPAGRI, 2020. Centro de Pesquisas Meteorológicas e Climáticas Aplicadas à Agricultura.

Climatologia Campinas. Disponível em: https://www.cpa.unicamp.br/graficos. Acesso em: 20 jan. 2021.

CETESB - Companhia Ambiental do Estado de São Paulo. Classificação expedita da representatividade espacial das estações de monitoramento da qualidade do ar da cetesb no Estado de São Paulo - Terceira Etapa, 2016. Disponível em: https://cetesb.sp.gov.br/ar/wpcontent/uploads/sites/28/2013/12/Relat\%C3\%B3rio-Classifica\%C3\%A7\%C3\%A3o TerceiraEtapa.pdf. Acesso em: 02 nov. 2020. 
CHARNET, R.; FREIRE, C.; CHARNET, E.; BONVINO, H. Análise de modelos de regressão linear com aplicações, 2008.

CONTINI, D.; COSTABILE, F. Does air pollution influence COVID-19 outbreaks? Atmosphere, v. 11, n. 4, p. 377, 2020. http://doi.org/10.3390/atmos 11040377

CUI, Y.; ZHANG, Z.; FROINES, J.; ZHAO, J.; WANG, H.; YU, S.; DETELS, R. Air pollution and case fatality of SARS in the People's Republic of China: an ecologic study. Environmental Health, v. 2, n. 1, p. 15, 2003. http://doi.org/10.1186/1476-069x-2-15

DANTAS, G.; SICILIANO, B.; FREITAS, L.; SEIXAS, E. G.; SILVA, C. M.; ARBILLA, G. Why did ozone levels remain high in Rio de Janeiro during the Brazilian truck driver strike? Atmospheric Pollution Research, v. 10, n. 6, p. 2018-2029, 2019. http://doi.org/10.1016/j.apr.2019.09.010

DANTAS, G.; SICILIANO, B.; FRANÇA, B. B.; SILVA, C. M.; ARBILLA, G. The impact of COVID19 partial lockdown on the air quality of the city of Rio de Janeiro, Brazil. Science Of The Total Environment, v. 729, p. 139085, 2020. http://doi.org/10.1016/i.scitotenv.2020.139085

DELTA - Economics \& Finance. Delta divulga o ranking $\mathrm{BCl}-\mathbf{1 0 0}$, com as $\mathbf{1 0 0}$ melhores cidades brasileiras, 2015.Disponível em:

http://deltaef.com/conhecimento6Det.asp?codParam=21. Acesso em: 10 ago. 2020.

DOCKERY, D. W.; EVANS, J. Tallying the bills of mortality from air pollution. The Lancet, v. 389, n. 10082, p. 1862-1864, 2017. http://doi.org/10.1016/s0140-6736(17)30884-x

IBGE - Instituto Brasileiro de Geografia e Estatística. Cidades e Estados. Disponível em: https://www.ibge.gov.br/cidades-e-estados/sp/campinas.html.2020. Acesso em: 10 ago. 2020.

INPE - Instituto Nacional de Pesquisas Espaciais. Queimadas. Disponível em: http://queimadas.dgi.inpe.br/queimadas/portal, 2020. Acesso em: 20 jan. 2021.

ISAIFAN, R. J. The dramatic impact of Coronavirus outbreak on air quality: has it saved as much as it has killed so far?. Global Journal Of Environmental Science And Management, v. 6, n. 3, p. 275-288, 2020. http://doi.org/10.22034/giesm.2020.03.01

JAYAWEERA, M.; PERERA, H.; GUNAWARDANA, B.; MANATUNGE, J. Transmission of COVID19 virus by droplets and aerosols: a critical review on the unresolved dichotomy. Environmental Research, v. 188, p. 109819, 2020. http://doi.org/10.1016/i.envres.2020.109819

LIN, H.; ZHANG, Y.; LIU, T.; XIAO, J.; XU, Y.; XU, X.; QIAN, Z.; TONG, S.; LUO, Y.; ZENG, W. Mortality reduction following the air pollution control measures during the 2010 Asian Games.

Atmospheric Environment, v. 91, p. 24-31, 2014. http://doi.org/10.1016/j.atmosenv.2014.03.051

LIU, Y.; NING, Z.; CHEN, Y.; GUO, M.; LIU, Y.; GALI, N. K.; SUN, L.; DUAN, Y.; CAI, J.;

WESTERDAHL, D. Aerodynamic analysis of SARS-CoV-2 in two Wuhan hospitals. Nature, v. 582, n. 7813, p. 557-560, 2020. http://doi.org/10.1038/s41586-020-2271-3

MAIER, B. F.; BROCKMANN, D. Effective containment explains subexponential growth in recent confirmed COVID-19 cases in China. Science, v. 368, n. 6492, p. 742-746, 2020.

http://doi.org/10.1126/science.abb4557

NAKADA, L. Y. K.; URBAN, R. C. COVID-19 pandemic: impacts on the air quality during the partial lockdown in São Paulo state, Brazil. Science of the Total Environment, v. 730, p. 139087, 2020. http://doi.org/10.1016/i.scitotenv.2020.139087 
NODA, L.; NÓBREGA, A. B. E. Q.; SILVA JÚNIOR, J. B. M.; SCHMIDLIN, F.; LABAKI, L. COVID19: Has social isolation reduced the emission of pollutants in the megacity of São Paulo - Brazil? Environment, Development and Sustainability, v. 23, p. 12233-12251, 2021. https://doi.org/10.1007/s10668-020-01166-2

NOGAROTTO, D. C.; RISSI, N. M.; POZZA, S. A. Um novo método de preenchimento de dados faltantes aplicado a séries temporais de concentração de MP10. Revista Tecnologia e Sociedade, v. 15, n. 37, p. 275-296, 2019. http://doi.org/10.3895/rts.v15n37.8594

QUALAR. Qualidade do ar no Estado de São Paulo. Disponível em: https://cetesb.sp.gov.br/ar/qualar/, 2020. Acesso em: 31 mar. 2020.

RITCHIE, H.; ROSER, M. Air Pollution. Our World in Data. Disponível em: https://ourworldindata.org/air-pollution. 2017. Acesso em: 10 jun. 2020.

RITCHIE, H.; ROSER, M. Outdoor Air Pollution. Our World in Data, 2019. Disponível em: https://ourworldindata.org/outdoor-air-pollution. Acesso em: 10 jun. 2020.

ROSSE, V. P.; PEREIRA, J. N.; BOARI, A.; COSTA, G. V.; RIBEIRO, J. P. C.; VIEIRA-FILHO, M. São Paulo's atmospheric pollution reduction and its social isolation effect, Brazil. Air Quality. Atmospheric \& Health, v. 14, p. 543-552, 2021. https://doi.org/10.1007/s11869-020-00959-8

SÃO PAULO. Adesão ao isolamento social em São Paulo. Disponível em: https://www.saopaulo.sp.gov.br/coronavirus/isolamento. 2020a. Acesso em: 01 jul. 2020.

SÃO PAULO. Decreto № 64.881, de 22 de março de 2020. Diário Oficial do Estado de São Paulo, São Paulo, 2020b.

SÃO PAULO. Decreto № 64.994, de 28 de maio de 2020. Diário Oficial do Estado de São Paulo, São Paulo, 2020c.

SÃO PAULO. Retomada consciente.2020d. Disponível em:

https://www.saopaulo.sp.gov.br/planosp/. Acesso em: 20 jan. 2020.

SEINFELD, J.; PANDIS, S. Atmospheric chemistry and physics: from air pollution to climate change. 3. ed. New Jersey, EUA: Wiley-Interscience, 2016.

SICILIANO, B.; CARVALHO, G.; SILVA, C. M.; ARBILLA, G. The Impact of COVID-19 Partial Lockdown on Primary Pollutant Concentrations in the Atmosphere of Rio de Janeiro and São Paulo Megacities (Brazil). Bulletin Of Environmental Contamination And Toxicology, v. 105, n. 1, p. 2-8, 2020. http://doi.org/10.1007/s00128-020-02907-9

SILVA, C. B. P.; SALDIVA, P. H. N.; AMATO-LOURENÇO, L. F.; RODRIGUES-SILVA, F.; MIRAGLIA, S. G. E. K. Evaluation of the air quality benefits of the subway system in São Paulo, Brazil. Journal Of Environmental Management, v. 101, p. 191-196, 2012.

http://doi.org/10.1016/i.jenvman.2012.02.009

TAVELLA, R. A.; SILVA, F. M. R. COVID-19 and air pollution: what do we know so far?. Vittalle Revista de Ciências da Saúde, v. 32, n. 1, p. 22-31, 2020.

http://doi.org/10.14295/vittalle.v32i1.11522

THE GUARDIAN. Coronavirus pandemic leading to huge drop in air pollution, 2020.

Disponível em: https://www.theguardian.com/environment/2020/mar/23/coronavirus-pandemicleading-to-huge-drop-in-air-pollution. Acesso em: 08 jun. 2020. 
WANG, Y.; WANG, Y.; CHEN, Y.; QIN, Q. Unique epidemiological and clinical features of the emerging 2019 novel coronavirus pneumonia (COVID-19) implicate special control measures. Journal of Medical Virology, v. 92, n. 6, p. 568-576, 2020. http://doi.org/10.1002/jmv.25748

WEISBERG, S. Applied Linear Regression. 3ª ed. John Wiley \& Sons, 2005.

WU, X.; NETHERY, R. C.; SABATH, M. B.; BRAUN, D.; DOMINICI, F. Exposure to air pollution and COVID-19 mortality in the United States: a nationwide cross-sectional study. Cold Spring Harbor Laboratory, 2020. Http://doi.org/10.1101/2020.04.05.20054502

YUAN, Z.; XIAO, Y.; DAI, Z.; HUANG, J.; CHEN, Y. A simple model to assess Wuhan lockdown effect and region efforts during COVID-19 epidemic in China Mainland. Cold Spring Harbor Laboratory, 2020. http://doi.org/10.1101/2020.02.29.20029561 